\title{
Computational Plume Modeling of Conceptual ARES Vehicle Stage Tests
}

\author{
Daniel C. Allgood ${ }^{1}$ \\ NASA Test Operations Group, Jacobs Technology, Stennis Space Center, MS, 39529 \\ Vineet Ahuja ${ }^{2}$ \\ Combustion Research and Flow Technology, Inc., Pipersville, PA, 18947
}

\begin{abstract}
The plume-induced environment of a conceptual ARES $V$ vehicle stage test at the NASA Stennis Space Center (NASA-SSC) was modeled using computational fluid dynamics (CFD). A full-scale multi-element grid was generated for the NASASSC B-2 test stand with the ARES $V$ stage being located in a proposed off-center forward position. The plume produced by the ARES $V$ main power plant (cluster of five RS-68 LOX/LH2 engines) was simulated using a multi-element flow solver CRUNCH. The primary objective of this work was to obtain a fundamental understanding of the ARES V plume and its impingement characteristics on the B-2 flame-deflector. The location, size and shape of the impingement region were quantified along with the un-cooled deflector wall pressures, temperatures and incident heating rates. Issues with the proposed tests were identified and several of these addressed using the CFD methodology. The final results of this modeling effort will provide useful data and boundary conditions in upcoming engineering studies that are directed towards determining the required facility modifications for ensuring safe and reliable stage testing in support of the Constellation Program.
\end{abstract}

\section{Nomenclature}

$\begin{array}{ll}\mathrm{A} & =\text { area } \\ \mathrm{C}_{1}, \mathrm{C}_{2} & =\text { turbulence modeling constants } \\ \mathrm{D} & =\text { diameter or source vector } \\ \mathrm{E} & =\text { energy } \\ f & =\text { turbulence empirical modeling functions } \\ \mathrm{F} & =\text { thrust or inviscid flux vector } \\ \mathrm{G} & =\text { viscous flux vector } \\ \mathrm{M} & =\text { Mach number } \\ \mathrm{P} & =\text { pressure } \\ \mathrm{Pr} & =\text { Prandtl number } \\ \mathrm{Q} & =\text { primary variable vector } \\ \mathrm{S} & =\text { species } \\ \mathrm{T} & =\text { temperature } \\ \mathrm{U} & =\text { velocity vector } \\ \mathrm{u}, \mathrm{v}, \mathrm{W} & =\text { velocity components } \\ \mathrm{x}, \mathrm{y}, \mathrm{z} & =\text { Cartesian coordinates } \\ \delta & =\text { impingement angle } \\ \varepsilon & =\text { turbulent kinetic energy dissipation rate }\end{array}$

\footnotetext{
${ }^{1}$ Sr. CFD Propulsion Engineer, AIAA Member.

${ }^{2}$ Research Scientist, AIAA Member.
} 


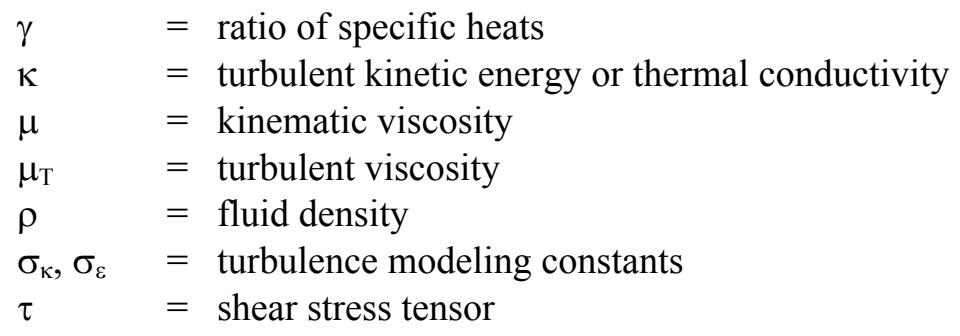

\section{Introduction}

\section{A. The Constellation Program}

Wnder the newly defined Constellation Program, NASA is endeavoring to broaden its manned space exploration efforts by returning back to the Moon by the year 2020. The mission durations on the lunar surface will be for much longer periods of time than that which were conducted during the Apollo Program. One of the primary objectives of this new exploration effort will be to develop both the experience and technology necessary for accomplishing future manned expeditions to Mars and beyond.

Two new transport vehicles, ARES V and ARES I, have been proposed to support the Constellation Program efforts ${ }^{1,2}$. Figure 1 shows the present day conceptual structure of the ARES vehicles. The corestage of the ARES V vehicle has an external casing diameter of $33 \mathrm{ft}$ and will be powered by five Pratt \& Whitney Rocketdyne RS-68 LOX/ $\mathrm{LH}_{2}$ engines ${ }^{3}$. The RS-68 engine is currently being used as the powerplant for the Delta IV expendable launch vehicle, and undergoing certification testing at the NASA Stennis Space Center, as shown in Figure 2a.

The Earth departure stage (EDS) of ARES V and the upper stage of ARES I (diameter of $18 \mathrm{ft}$ ) will both be powered by single J-2X engines. The J-2X engine, also to be manufactured by Pratt \& Whitney Rocketdyne, is not currently under production. It will consist of a blend of the Apollo-era J-2 engine that powered the $2^{\text {nd }}$ and $3^{\text {rd }}$ stage of the Saturn V, and the streamlined J-2S engine which was developed and tested in the late 1970's but never flew. A conceptual rendering of the J-2X is depicted in Figure 2b. The planned engine specifications for the new ARES power plants are summarized in Table $1^{4-7}$.

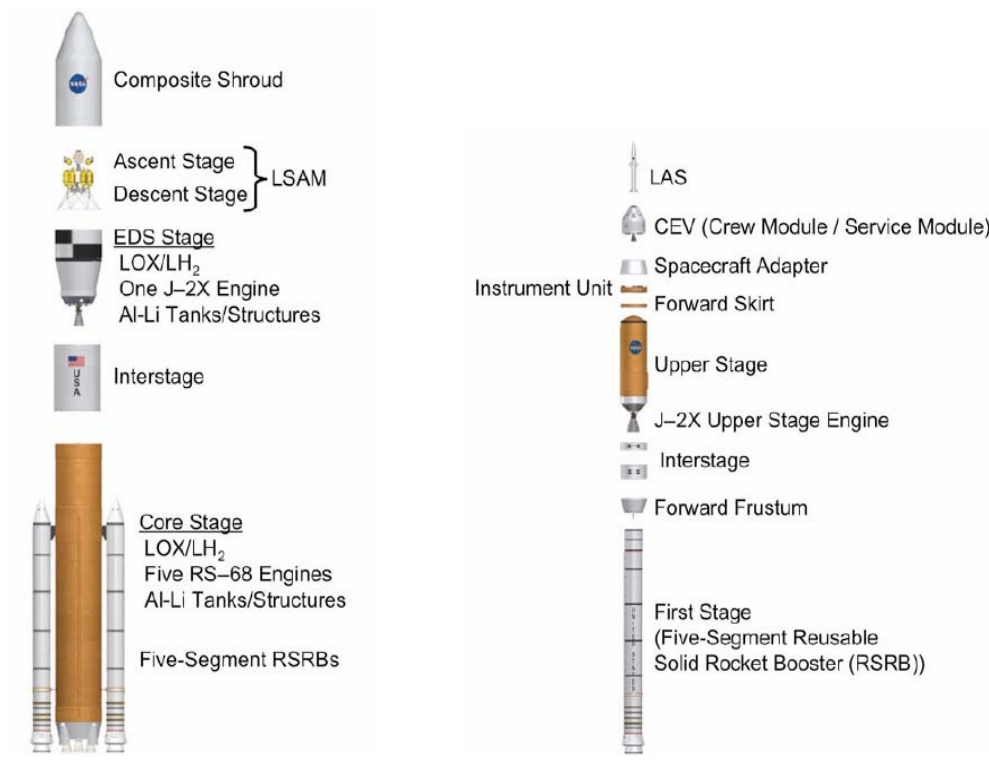

Figure 1: ARES V (left) and ARES I (right) Vehicles ${ }^{1,2}$ 

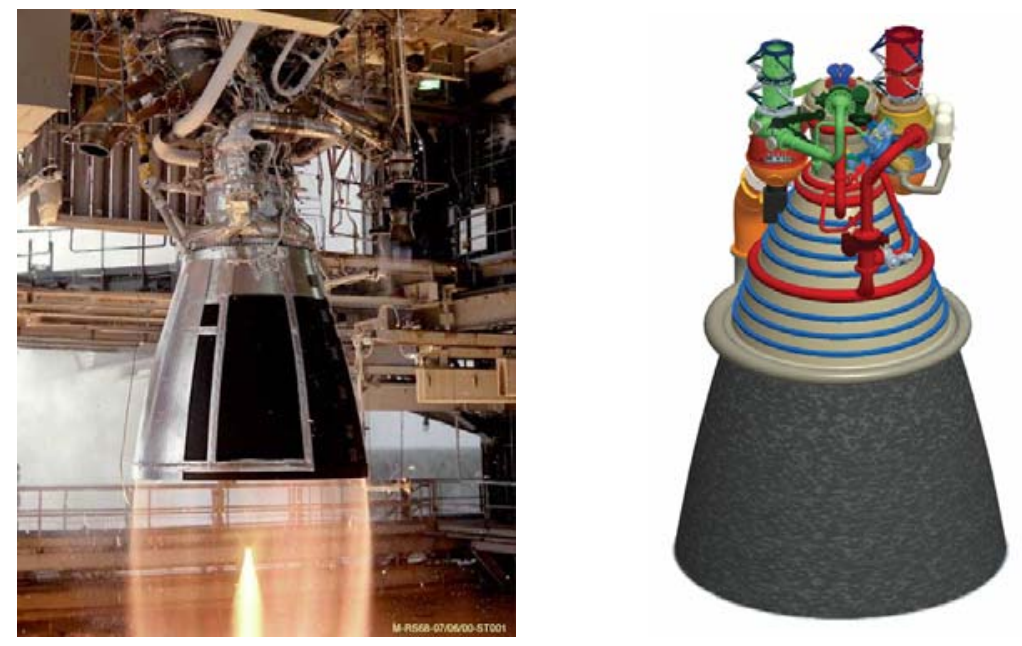

Figure 2: An RS-68 Engine Test at the NASA Stennis Space Center B-1 Test Facility and a Conceptual Rendering of the J-2X Engine ${ }^{1,2}$

Table 1: Conceptual RS-68 and J-2X Engine Specifications

\begin{tabular}{ccc}
\hline & $\boldsymbol{R S}-\mathbf{6 \boldsymbol { 8 } ^ { 4 , 5 }}$ & $\boldsymbol{J}-\mathbf{2} \boldsymbol{X}^{\mathbf{6 , 7}}$ \\
\hline Engine Cycle & Gas Generator & Gas Generator \\
Propellants & LOX/LH & $\mathrm{LOX}_{2} \mathrm{LH}_{2}$ \\
Mixture Ratio & 6.0 & 5.5 \\
Chamber Pressure (psia) & 1450 & 1338 \\
Thrust (K-lbf) & $758(\mathrm{v}) / 663(\mathrm{sl})$ & $294(\mathrm{v})$ \\
Isp (sec) & $409(\mathrm{v}) / 357(\mathrm{sl})$ & $448(\mathrm{v})$ \\
Expansion Area Ratio & 21.5 & - \\
Exit Diameter (in) & 96 & - \\
\hline
\end{tabular}

\section{B. Vehicle Stage Testing Capability at NASA-SSC}

In preparation for the Constellation Program, proposals for NASA Stennis to conduct both ARES V and ARES I stage tests are being made. The B-2 test facility at NASA Stennis is a prime candidate for conducting these stage tests due to its unique capabilities, which are highlighted in Table 2. The B-2 test facility has been used in the past to test a variety of vehicle stages including the Apollo SATURN V, Space Shuttle Main Propulsion Test Article (MPTA), and the Delta IV common booster core (CBC). Historical images of these test programs are shown in Figure 3. The SATURN V booster stage was the most powerful of the three, generating an aggregate thrust of $7.76 \times 10^{6} \mathrm{lbf}$ (or $7.76 \mathrm{M}-\mathrm{lbf}$ ) from 5 LOX/RP-1 F-1 engines. In comparison, the ARES V core-stage and ARES I EDS will deliver much less thrust of only 3.25 and $0.3 \mathrm{M}-\mathrm{lbf}$, respectively. The Space Shuttle MPTA, shown mounted on the B-2 test stand in Figure 3b, was composed of an external tank, shuttle tail structure, and the 3-engine Space Shuttle Main Engine (SSME) cluster. The aggregate thrust for the Space Shuttle MPTA was 1.5 M-lbf. More recently, the Delta IV CBC, powered by the $700 \mathrm{~K}-1 \mathrm{bf}$ class RS-68 engine, was tested at the B-2 test facility (Figure 3c). 
Table 2: NASA Stennis Space Center B-1 \& B-2 Test Facility Capabilities ${ }^{8}$

- Thrust capability of $13 \mathrm{M}-\mathrm{lb}$

- Flame-deflector Cooling of 330,000 gal/ min

- Deluge System of $123,000 \mathrm{gal} / \mathrm{min}$

- Data measurement system

- Two derricks - 175 ton and 200 ton

- High- pressure gas distribution systems

- LOX and LH2 propellant supply systems

- Hazardous gas and fire detection systems

- Barge unloading capability (3 LOX, 3 LH)

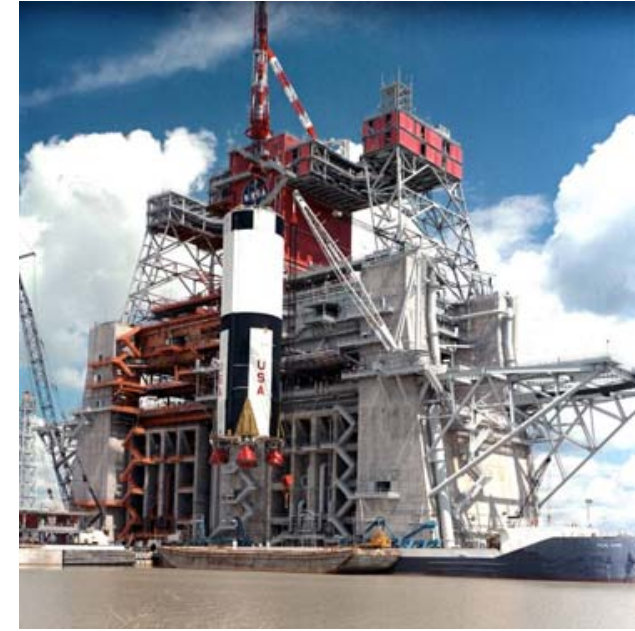

(a)

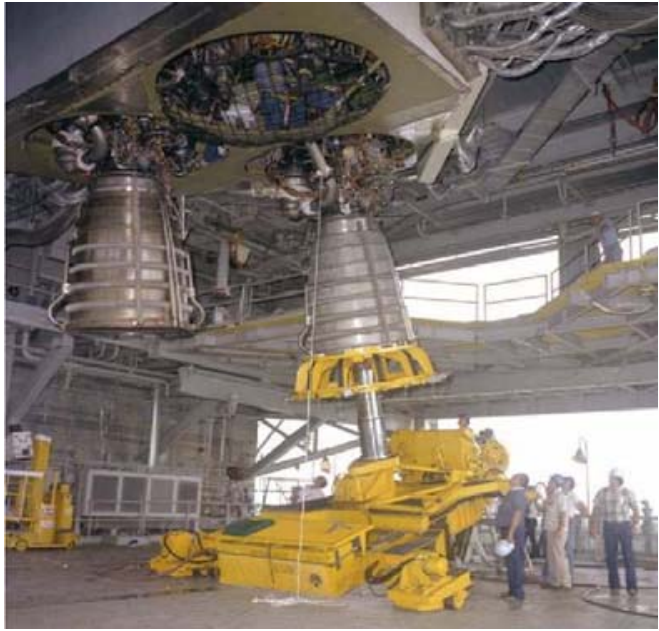

(b)

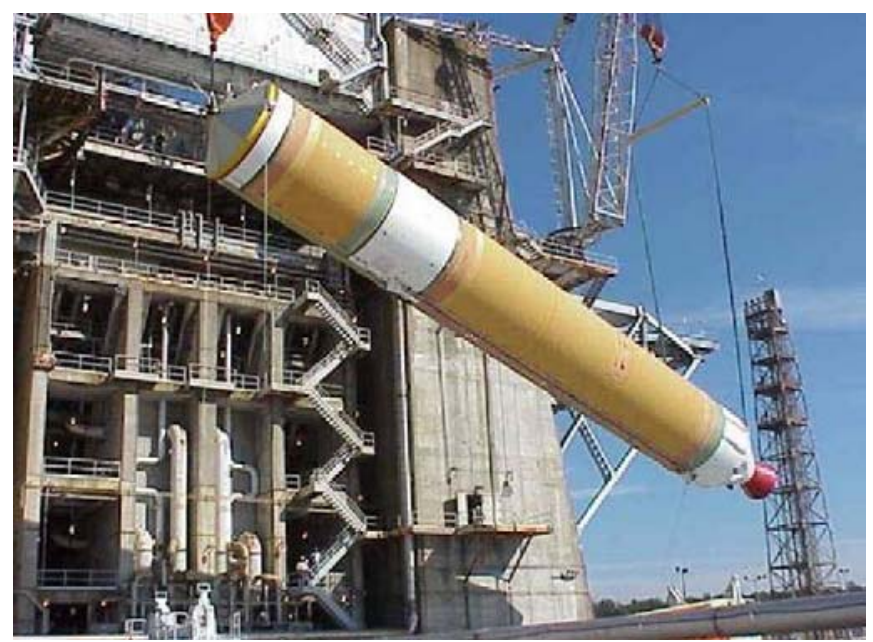

(c)

Figure 3: Vehicle Stage Tests at the NASA Stennis Space Center B-2 Test Facility (a) SATURN V Core Stage, (b) Space Shuttle Main Propulsion Test Article (MPTA) and (c) Delta IV Common Booster Core (CBC) Stage 


\section{Problem Description}

Due to stringent test scheduling demands and limited test facility resources, the question was posed concerning the feasibility of having both ARES stages on the B-2 test facility during a single ARES stage test. This would prevent having to unload one stage while the other was being tested. It should be made clear that no plans are made to conduct tests of the ARES V and ARES I stages simultaneously but rather solely to avoid having to relocate one of the stages during a test.

Figure 4 is a dimensionally accurate PRO-E CAD model illustrating the proposed arrangement of the ARES $\mathrm{V}$ in a forward (Northern) position on the B-2 test stand and the ARES I in an aft (Southern) position. The relative placement of the stages on the stand was governed by a combination of the test demands and geometric/facility constraints of the B-2 test stand. For example, due to the foreseen probability that the ARES I would be loaded and unloaded more frequently than the ARES V stage, the ARES I had to be located in the aft location which is closest to the test stand crane. Furthermore, geometric constraints imposed by the upper support structure, aspirator and flame-deflector prevented any East/West arrangement of the two ARES stages.

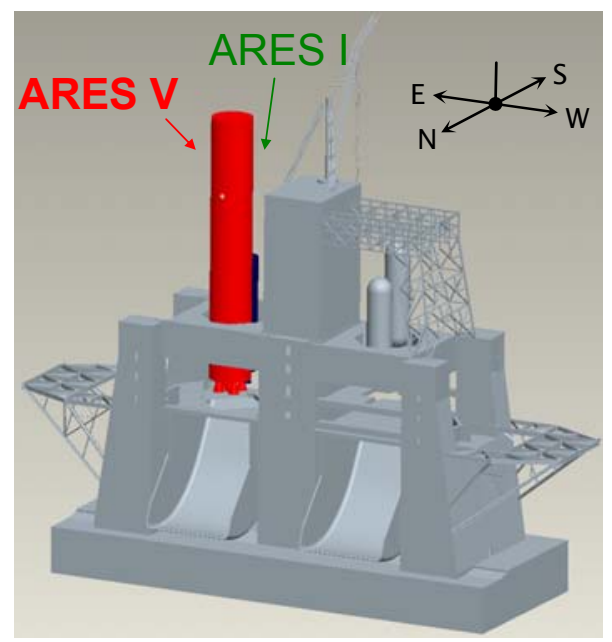

Figure 4: Dimensionally Accurate PRO-E CAD Model of the Proposed Arrangement for the ARES $V$ and ARES I Stages on the NASA Stennis B-2 Test Stand

Figure 5 is a side-view representation of the proposed arrangement for the shared B-2 facility which depict the critical angles and dimensions. The dimensions have been normalized by the RS- 68 engine nozzle exit diameter. Upon first review, several potential issues were raised concerning the stage testing of ARES V. First, it was feasible that an undesirable ARES V plume deflection might occur due to a stronger impingement angle on the deflector surface $\left(47.5^{\circ}\right.$ vs. $\left.43.2^{\circ}\right)$ compared to an aspirator centered configuration. The larger plume-impingement angle could result in a detached impingement shock, which would induce reversed flow upstream along the deflector surface. The stronger impingement heat transfer and resulting reversed flow convective heating would require modifications to the deflector water cooling-hole spacing to be made. Since a sufficient amount of cooling water (330,000 gallons/minute) is available through the facility industrial water supply, only modifications to the cooling-hole patterns along the deflector surface would be needed.

In addition to the plume impingement region, increased convective and radiative heating of the aspirator could also be expected due to the ARES V plume being located closer to the aspirator walls compared to an aspirator-centered placement of the ARES V. Finally, the acoustic and vibrational loading to the neighboring ARES I imposed by the ARES V stage tests is a significant unknown which cannot be overlooked. However, the current CFD modeling effort was focused solely on quantifying the 
plume impingement properties for the ARES $\mathrm{V}$ tests and providing guidance on cooling modifications that might need to be made to the test stand.

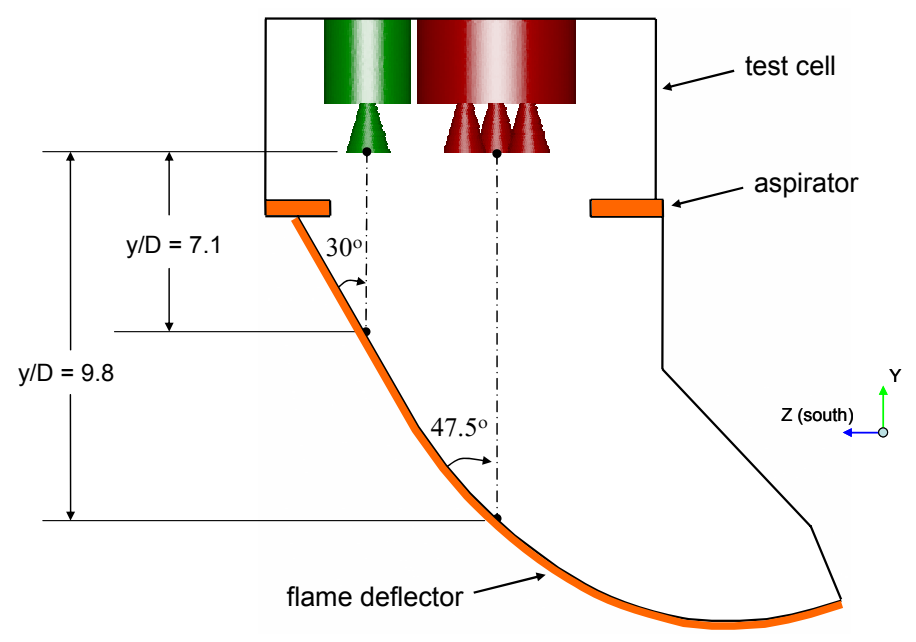

Figure 5: Proposed Placement of the ARES V (in red) and the ARES I (in green) Stages on the NASA Stennis B-2 Test Stand (in orange)

\section{Modeling Approach}

\section{A. CRUNCH CFD Code Description}

The modeling and simulation group at NASA Stennis have been successfully implementing the CRUNCH CFD code for a variety of fluid-flow problems including valves, cavitating venturies, cryogenic propellant tanks, and reacting rocket plumes. $\mathrm{CRUNCH}^{12-14}$ is a multi-element (i.e. tetrahedral, prismatic, pyramid, and hexahedral cells) unstructured flow solver for viscous, real gas systems. It is formulated for an edge-based data framework (following Barth ${ }^{15,16}$ ) where the solution is saved at the cell-vertex and a dual control-volume is defined by cutting across all edges coming to a node. Such an edge-based formulation is attractive when dealing with multi-elements since the dual surface associated with an edge can include contributions from different element types resulting in a "grid transparent" framework for inviscid flows.

The governing equations being solved in $\mathrm{CRUNCH}$ are written in finite-volume form for each vertex dual control-volume as follows:

$$
\frac{\partial}{\partial t} \int_{\Omega} Q d V+\int_{\partial \Omega} F(Q, n) d s=\int_{\partial \Omega} G(Q, n) d s+\int_{\Omega} D d V
$$

Following the standard notation, $\mathrm{Q}$ is the vector of dependent variables, $\mathrm{F}(\mathrm{Q}, \mathrm{n})$ is the inviscid flux vector, $\mathrm{G}(\mathrm{Q}, \mathrm{n})$ is the viscous flux vector, and $\mathrm{D}$ is the chemical/turbulent source term. The vectors $\mathrm{Q}, \mathrm{F}, \mathrm{G}, \mathrm{D}$ are defined as

$$
Q=\left[\rho, \rho u, \rho v, \rho w, E, \rho_{1}, \ldots, \rho_{s}, \ldots, \rho_{N S-1}, \rho k, \rho \varepsilon\right]^{T}
$$




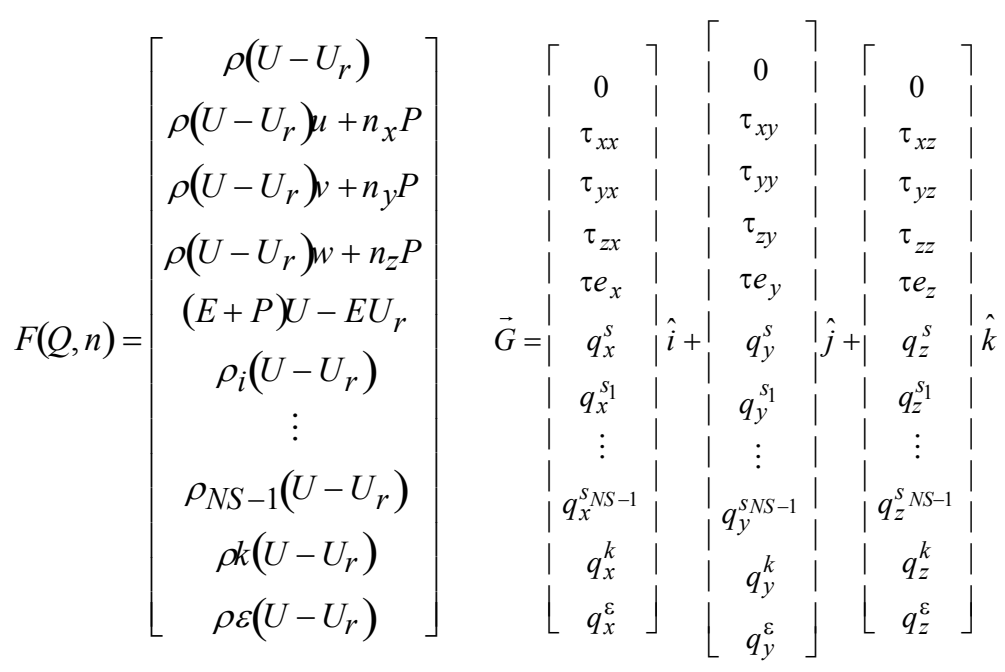

where

$$
\begin{aligned}
& \tau e_{x}=\tau_{x x} u+\tau_{x y} v+\tau_{x z} w-q_{x}^{h}+\sum_{i=1}^{N S-1}\left(h_{i}-h_{N S}\right) q_{x}^{S_{i}} \\
& \tau e_{y}=\tau_{y x} u+\tau_{y y} v+\tau_{y z} w-q_{y}^{h}+\sum_{i=1}^{N S-1}\left(h_{i}-h_{N S}\right) q_{y}^{S_{i}} \\
& \tau e_{z}=\tau_{z x} u+\tau_{z y} v+\tau_{z z} w-q_{z}^{h}+\sum_{i=1}^{N S-1}\left(h_{i}-h_{N S}\right) q_{z}^{S_{i}}
\end{aligned}
$$

The first five equations represent global continuity, momentum, and energy equations; the next (NS-1) equations represent species continuity; and, the last two equations represent scalar transport of turbulent kinetic energy and dissipation rate.

The inviscid flux procedure involves looping over the edge list and computing the flux at the dual face area bisecting the edge. A Riemann problem is solved for using higher order reconstructed values at the dual face (see Ref. 12 for details). Presently, a second-order linear reconstruction procedure (following Barth $^{15}$ ) is employed to obtain a higher order scheme. The higher-order variables need to be limited to yield a total variation diminishing (TVD) scheme. We note that the inviscid flux procedure as outlined here is grid transparent in that the details of the different element types contributing to a dual face area edge are not relevant.

The viscous fluxes are computed by estimating the gradients (or stresses) at the cell faces and then performing a Green-Gauss integration of the stresses around each dual control volume [see Ref. 13 for details]. For hexahedral cells where the edge vectors are not skewed relative to the cell faces, an edgebased viscous flux procedure can be derived. However, for tetrahedral cells where edge skewness is substantial, the edge based procedure fails, particularly for the k- $\varepsilon$ equations, and is reflected in incorrect turbulent viscosity levels. For tetrahedral cells, a cell based procedure has been implemented which remedies this problem.

The 'standard' high Reynolds number form of the $k-\varepsilon$ equations forms the basis for turbulence modeling in CRUNCH. Transport equations for the turbulent kinetic energy and its dissipation rate are solved along with the basic momentum and energy equations. These equations, with supplemental low Re near-wall terms, are as follows, 


$$
\begin{gathered}
\frac{\partial \rho k}{\partial t}+\frac{\partial}{\partial x_{i}}\left(\rho u_{i} k-\left(\mu+\frac{\mu_{T}}{\sigma_{k}}\right) \frac{\partial k}{\partial x_{i}}\right)=P_{k}-\rho \varepsilon+S_{k} \\
\frac{\partial \rho \varepsilon}{\partial t}+\frac{\partial}{\partial x_{i}}\left(\rho u_{i} \varepsilon-\left(\mu+\frac{\mu_{T}}{\sigma_{\varepsilon}}\right) \frac{\partial \varepsilon}{\partial x_{i}}\right)=C_{1} f_{1} P_{k}-C_{2} f_{2} \rho \varepsilon+S_{\varepsilon} \\
\mu_{T}=C_{\mu} f_{\mu} \rho \frac{k^{2}}{\varepsilon}
\end{gathered}
$$

where, $\sigma_{k}, \sigma_{\varepsilon}, \mathrm{C}_{1}$ and $\mathrm{C}_{2}$ are the modeling constants, and $f_{1}, f_{2}, f_{\mu}$ are low Re (near-wall) empirical modeling functions which equal unity in the high Reynolds number form.

Corrections to the k- $\varepsilon$ turbulence model equations are often required to account for the effects of compressibility and non-linearity. A compressible wall function serves as a baseline method for nearwall analysis but does not perform adequately for highly separated regions. Extended variants of ke that account for non-linear effects may be required to handle the complex vortical physics such as observed in mixing regions in scramjets. Three primary upgrades have been implemented in CRUNCH namely: (1) $\mathrm{n}^{+}$based near wall low Reynolds number models to enable integration to the walls; (2) compressibility corrections of Sarkar to account for effects of compressible-dissipation and pressure-dilation; and (3) an Explicit Algebraic Stress Model (EASM) to include non-linear effects. These extensions are described in Ref. 14. The EASM model, in particular, is shown to significantly improve predictions in complex vortical flow regions, by allowing the model parameter $\mathrm{C}_{\mu}$ to vary as a function of the local flow conditions, as opposed to being a constant as in the traditional k- $\varepsilon$ models. Developmental work includes accounting for variable $\mathrm{Pr}_{\mathrm{t}} / \mathrm{Sc}_{\mathrm{t}}$ effects ${ }^{17}$ and using probability density function (PDF) turbulent combustion models ${ }^{18}$.

The scalar equation extensions described in equation set (1) allow for the analysis of generalized, multi-component gaseous flowfields including real gas behavior. Non-equilibrium combustion phenomenon can be modeled using finite rate chemical kinetic source terms in a completely general fashion where an arbitrary set of reactions may be specified by the user. The reader is referred to Ref. 12 for more details on the combustion modeling approach implemented in CRUNCH.

For efficient computation of large 3D problems, a parallel framework for distributed memory systems has been implemented along with an implicit solution procedure for the sparse implicit Jacobian matrix. The parallel framework is implemented by partitioning the grid into sub-domains with each sub-domain residing on an independent processor. Since the solution is solved for at the cell vertex, the control volume for the nodes lying on the interprocessor boundaries may span across processors. The net flux for the interprocessor nodes are obtained by summing up the fluxes computed independently on each processor and hence the explicit flux is identical to the single-processor solution (see Ref. 16 for details). The message passing between processors has been implemented using MPI to provide portability across various platforms.

The implicit solution procedure allows for Gauss-Seidel or generalized minimum residual (GMRES) ${ }^{16}$ solver options with a preconditioning matrix using distance-one neighbor bandwidth. Currently, the approximate Jacobian for the Roe-average flux is taken and this together with the sparseness of the preconditioning matrix may affect the stability of the inversion procedure. The implicit inversion process is implemented for parallel, partitioned grids by summing up the diagonal blocks of the sparse matrix for interprocessor nodes. The off-diagonal blocks for inter-processor nodes can be made zero to ensure identical solutions on each processor. In this case, the stability of the procedure would depend on the diagonal dominance of the system. Conversely, if the off- diagonal blocks were not made zero, the solution on interprocessor nodes would need to be averaged across processors to obtain a common solution on all processors. 


\section{B. Modeling Assumptions}

The overall primary assumption being made in the current work was to neglect the effects of the flame-deflector cooling water on the ARES V plume structure, i.e. to model the "wet-plume" as a "dryplume". This assumption was found to be necessary due to the fact that it was not computationally feasible to accurately model the flow from thousands of 5/32-inch diameter cooling holes on the flamedeflector. While an approximation of the cooling flow could have been made by applying a porous wall model, the the capability of CRUNCH in modeling the two-phase evaporation flow physics associated with the water injection process is currently under development. However, it should be noted here that the basic structure of the physical "wet-plume" will be very similar to the "dry-plume" in terms of its impingement and attachment characteristics on the flame-deflector. Therefore, the dry-plume model will provide the capability of predicting the maximum possible heat loads that could occur on the B-2 cooled flame-deflector surface. These results can then provide guidance on determining any cooling-hole modifications that might be required to safely conduct the future ARES stage testing programs. In conclusion, the results of the current work are believed to be highly valuable despite the necessary simplifying assumptions being made in the models.

The ARES V plume was also modeling assuming ideal-gas chemically frozen flow. The viscous boundary layer effects were neglected initially by solving the Euler-equations on fully unstructured grids. This allowed for accelerated grid generation and reduced numerical overhead during this preliminary effort. Viscous turbulent modeling of the plume are now being conducted on multi-element grids with structured hexagonal grid cells placed in the viscous dominated areas (e.g. plume shear layers, deflector boundary layers, etc.).

\section{Computational Domain and Boundary Conditions}

The dimensionally accurate full-scale CAD model of the B-2 test stand with the ARES vehicles and their associated engines in the proposed locations on the stand was shown in Figure 4. The CAD model was exported from PRO-E as an IGES file and the trimmed surfaces in the IGES file were used as the database curves for generating the CFD grid. Figure 6 depicts the computational domain defined and the final multi-block grid sizes used in the current work. Care was taken to cluster the grid cells where strong gradients in the flowfield where expected such as the engine exhaust, aspirator and flame-deflector regions. A grid-independency study was also performed which verified adequate resolution in the flowfield.

The critical RS-68 chamber conditions and engine dimensions were obtained from publicly available sources and were summarized in Table 1 . The NASA chemical equilibrium analysis (CEA) code ${ }^{10}$ was then used to determine the nozzle exit conditions in order to apply the appropriate engine inflow boundary conditions in the CFD model. The output from this CEA analysis is summarized in Table 3.

Table 3: RS-68 Nozzle Exit Conditions Predicted by the NASA CEA Code

\begin{tabular}{lc}
\hline \multicolumn{2}{c}{ RS-68 Nozzle Exit Conditions $(C E A)$} \\
\hline$\rho\left(\mathrm{kg} / \mathrm{m}^{3}\right)$ & $4.73 \mathrm{e}-2$ \\
$\mathrm{P}(\mathrm{Pa})$ & 47191.0 \\
$\mathrm{~T}(\mathrm{~K})$ & 1672.0 \\
$\mathrm{Mach}$ No. & 3.7 \\
$\mathrm{c}(\mathrm{m} / \mathrm{sec})$ & 1098.6 \\
$\gamma$ & 1.23 \\
\hline
\end{tabular}




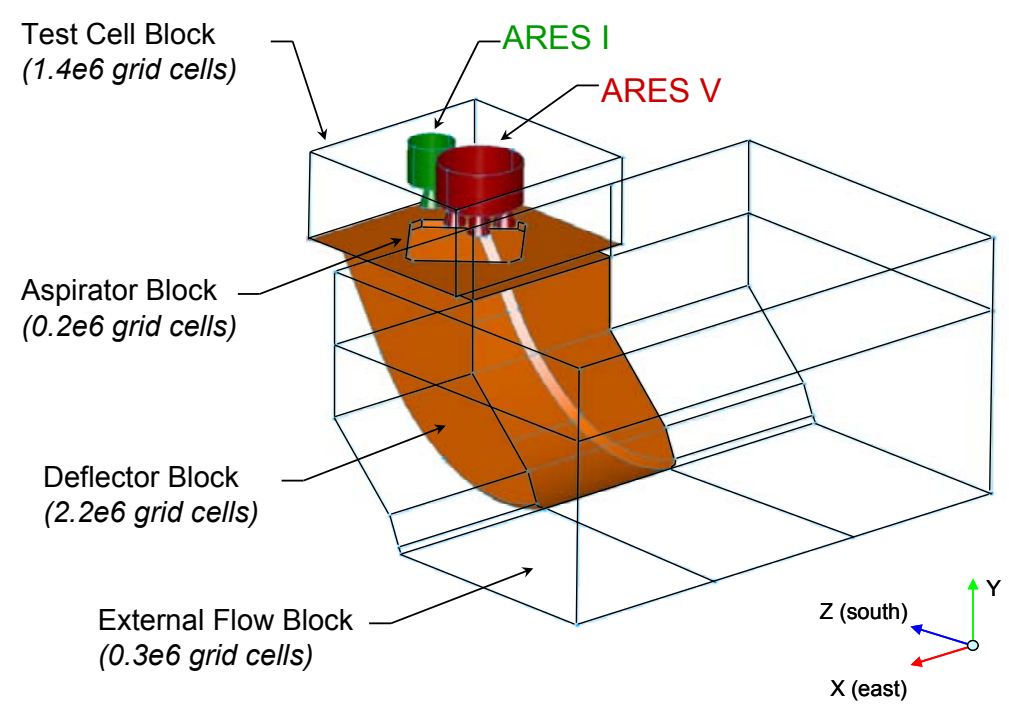

Figure 6: Multi-Block CFD Grid Domain for the ARES V B-2 Plume Impingement Model (4.2 million grid cells total)

Using the properties in Table 3, the 5 RS-68 nozzle exits were modeled as fixed-flux boundary conditions. The test cell and external flow entrainment boundaries depicted in Figure 6 were specified to be subsonic inlet boundaries at standard sea-level conditions to allow atmospheric entrainment by the plume. The walls of the vehicles, aspirator, flame-deflector and external ground were all modeled as inviscid walls during the preliminary stages of this work. The outflow boundary in the external flow block, shown in Figure 6, was specified to be a mixed supersonic/subsonic flow exit boundary. During the course of this work, it was determined to be critical in the model that a sufficiently large external flow block be included in the computational domain in order to accurately capture the entrainment and recirculating flow inside the flame-deflector, as well as the natural plume expansion external to the flamedeflector. Placing the external flow boundary conditions too close to the flame-deflector was observed to alter the flow pattern inside the deflector. The external flow block depicted in Figure 6, with 0.3e6 grid cells, was found to be sufficient for the current work. In addition, due to structural asymmetry in the test stand test cell area as shown in Figure 4, it was initially unclear that the assumption of flow symmetry at the centerline plane through the deflector was valid. Therefore, the entire B-2 test stand was modeled without assuming symmetry. In the next section of this paper, it will be evident that the modeling results show the time-averaged or "steady-state" plume to be highly symmetric, thus the assumption of symmetry would have been valid for steady-steady simulations.

\section{Results and Discussions}

Figures 7 and 8 are the computed time-averaged temperatures and pressures of the ARES vehicles, B-2 aspirator, B-2 flame-deflector, and external ground surface. The impingement zone on the flamedeflector was characterized by a maximum un-cooled wall temperature of $2600 \mathrm{~K}\left(4220^{\circ} \mathrm{F}\right)$ and a stagnation pressure of $4.2 \mathrm{e} 5 \mathrm{~Pa}(61 \mathrm{psi})$. Significant heating by the attached plume is also seen to occur in Figure 7 along the sidewalls of the deflector. This is due to the "splashing" effect of the plume on the deflector sidewalls, and might suggest modifications to be made to the cooling hole spacing in these locations.

One key observation critical to this work, was that most of the plume was attached and deflected down the deflector surface as desired. Shock cells in the attached plume are indicated by the high-temperature semi-circular regions on the flame-deflector as seen in Figure 7 . Figure 8 shows that these high- 
temperature shock regions are accompanied by high-pressure zones on the flame-deflector. Figure 9 is the same wall pressure contours of Figure 8 but with an overlay of the significant shock-surfaces (in orange) which were present in the flow. Figure 9 clearly shows shock surfaces associated with each of the over-expanded RS-68 engine nozzles. A single inclined plume-impingement shock was also seen just above the impingement zone which redirected the supersonic flow along the deflector surfaces. The plume-impingement shock was then followed by a series of shock cells in the attached plume. Significant over-expansion of the attached plume was also observed as the plume exited the deflector which resulted in a strong normal shock along the ground surface as seen in Figure 9.

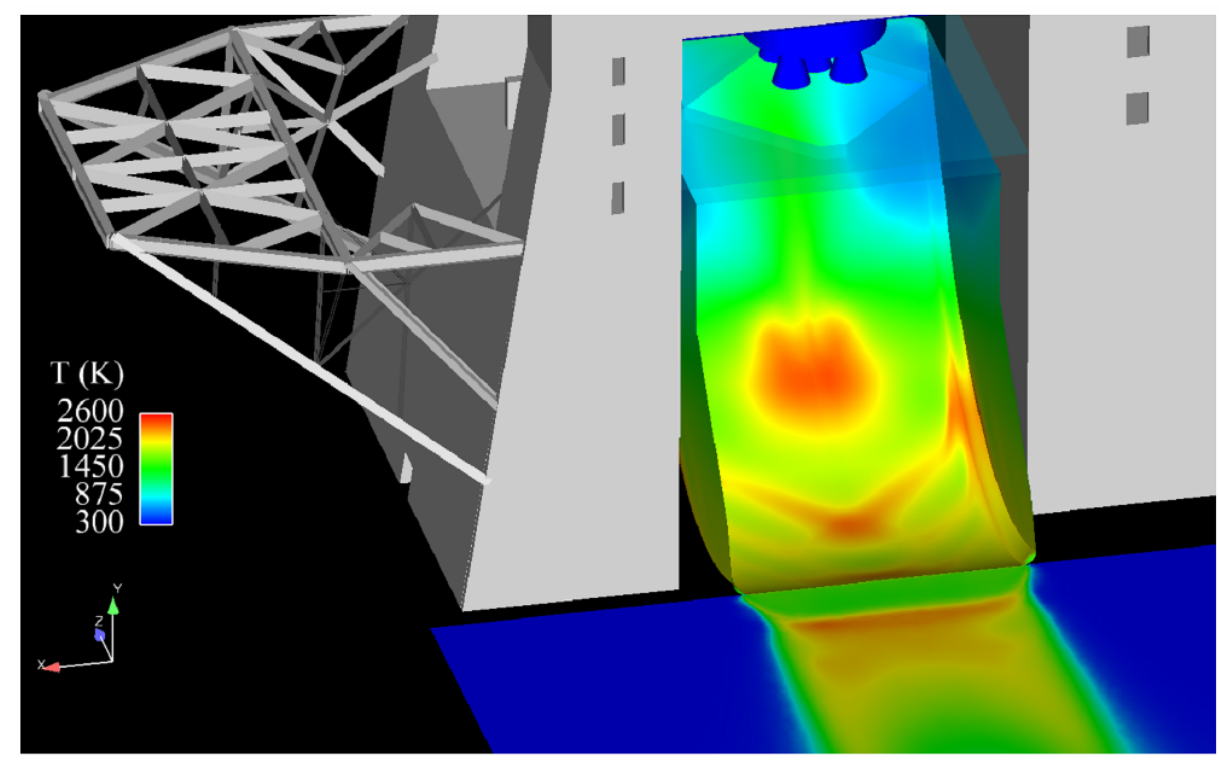

Figure 7: Time-Averaged Wall Temperatures Produced by the ARES V Plume

Three B-2 flame-deflector surface profiles of pressure and temperature have been plotted in Figures $10 \mathrm{a}$ and $10 \mathrm{~b}$ respectively. The impingement pressures and temperatures have been plotted as a function of the normalized transverse coordinate direction $(\mathrm{x} / \mathrm{D})$, where $\mathrm{D}$ is the RS-68 engine nozzle exit diameter. The coordinate directions are consistent with that depicted in previous figures. Each profile corresponds to a position directly under a set of engines for the ARES V engine cluster. More specifically, the surface profiles directly under the center RS- 68 engine are designated as $\mathrm{z} / \mathrm{D}=0$; the profiles directly under the two upstream engines are designated as $\mathrm{z} / \mathrm{D}=0.6$; and the profiles directly under the two downstream engines are designated as $\mathrm{z} / \mathrm{D}=-0.6$. Figure 10 shows that the highest impingement pressures and temperatures occur almost directly under the ARES V vehicle as expected. Analytically, it can be shown that the impingement pressure can be estimated based on the engine thrust (F), plume crosssectional area $\left(\mathrm{A}_{\text {imp }}\right)$, and the impingement angle $(\delta)$. Equation 6 below was derived assuming perfect plume deflection, steady-state, and incompressible flow.

$$
P_{\text {impingement }}=\frac{F^{*} \sin \delta}{A_{i m p}}
$$

Using equation (6), the impingement pressure for a 5-engine RS-68 cluster array was estimated to be $4.32 \mathrm{e} 5 \mathrm{~Pa}$ at the center impingement point, where a hydraulic plume diameter of $\mathrm{n}^{1 / 2} * \mathrm{D}$ was used. The CFD calculations predicted a maximum impingement pressure of $4.2 \mathrm{e} 5 \mathrm{~Pa}$, which is within $3 \%$ of the analytical estimate. 
The upstream profiles $(\mathrm{z} / \mathrm{D}=0.6)$ in Figures $10 \mathrm{a}$ and $10 \mathrm{~b}$ show distinctly the off-center impingement of the 5-engine cluster indicating that the individual engine plumes had not coalesced into a single plume before impacting the flame-deflector. An increase in deflector wall temperatures and pressures were also observed near the deflector side walls $($ at $\mathrm{x} / \mathrm{D}=4.0)$ due "splash" impingement of the attached plume. The highest pressure and temperatures due to the sidewall impingement were observed to occur downstream indicating the majority of the flow was being appropriately directed down the flame-deflector surface.

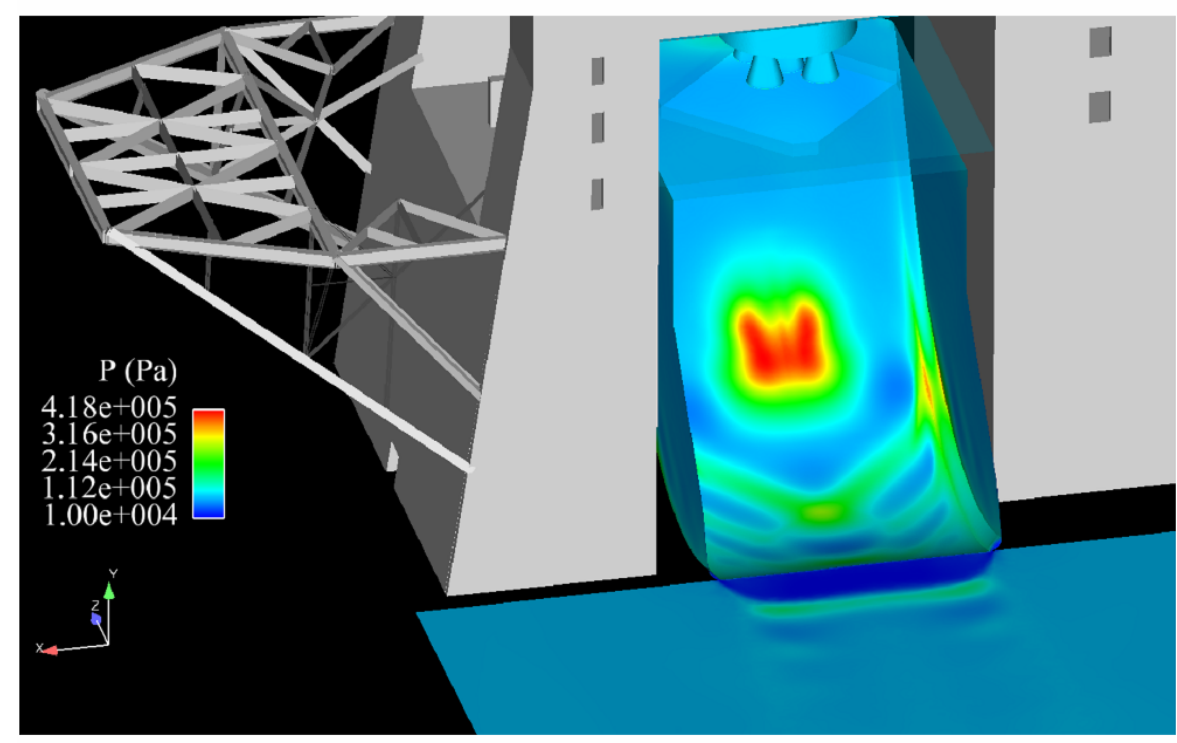

Figure 8: Time-Averaged Wall Pressures Produced by the ARES V Plume

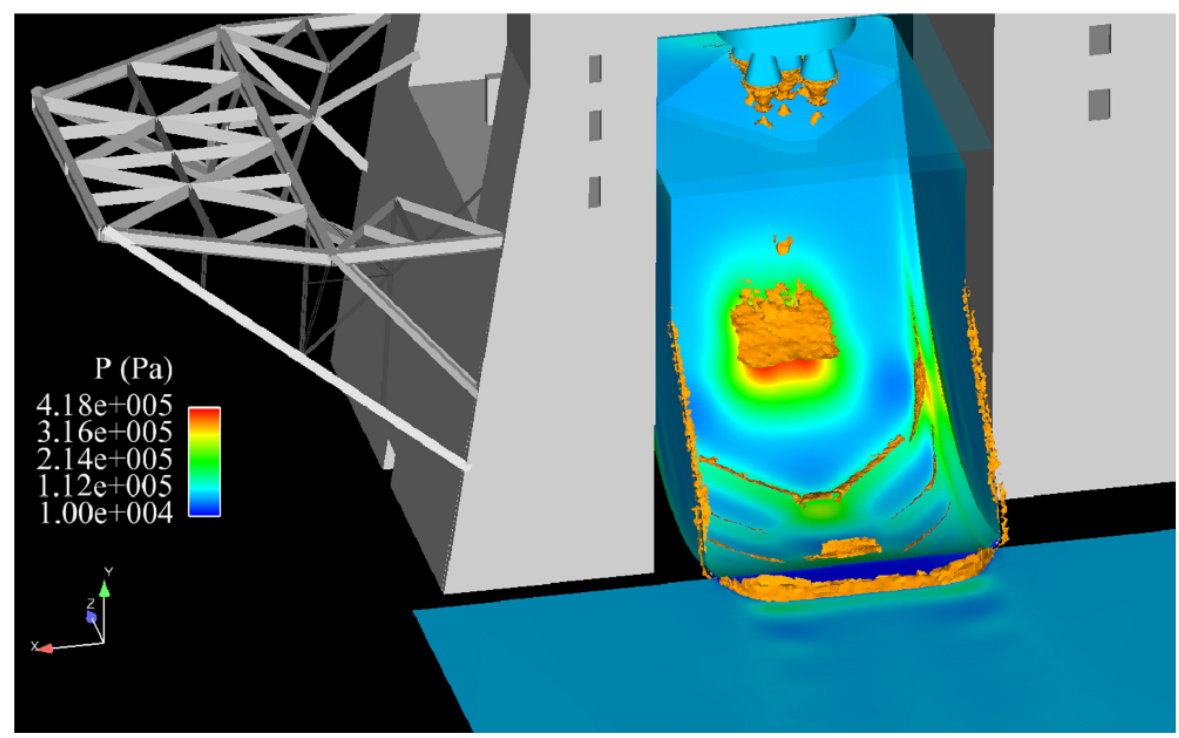

Figure 9: Overlay of Shock Surfaces (Orange) on to the Time-Averaged Wall Pressures Produced by the ARES V Plume 


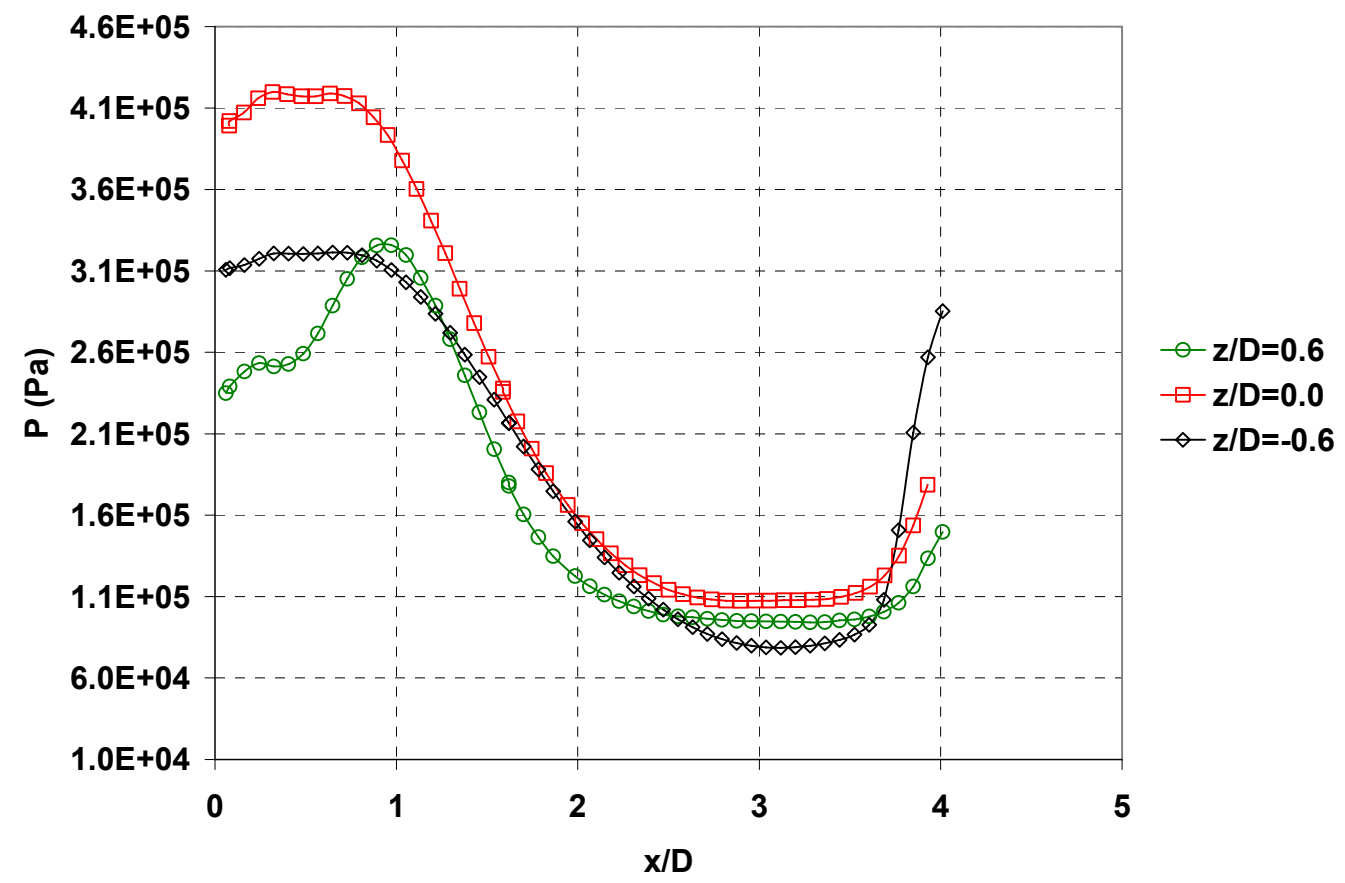

(a)

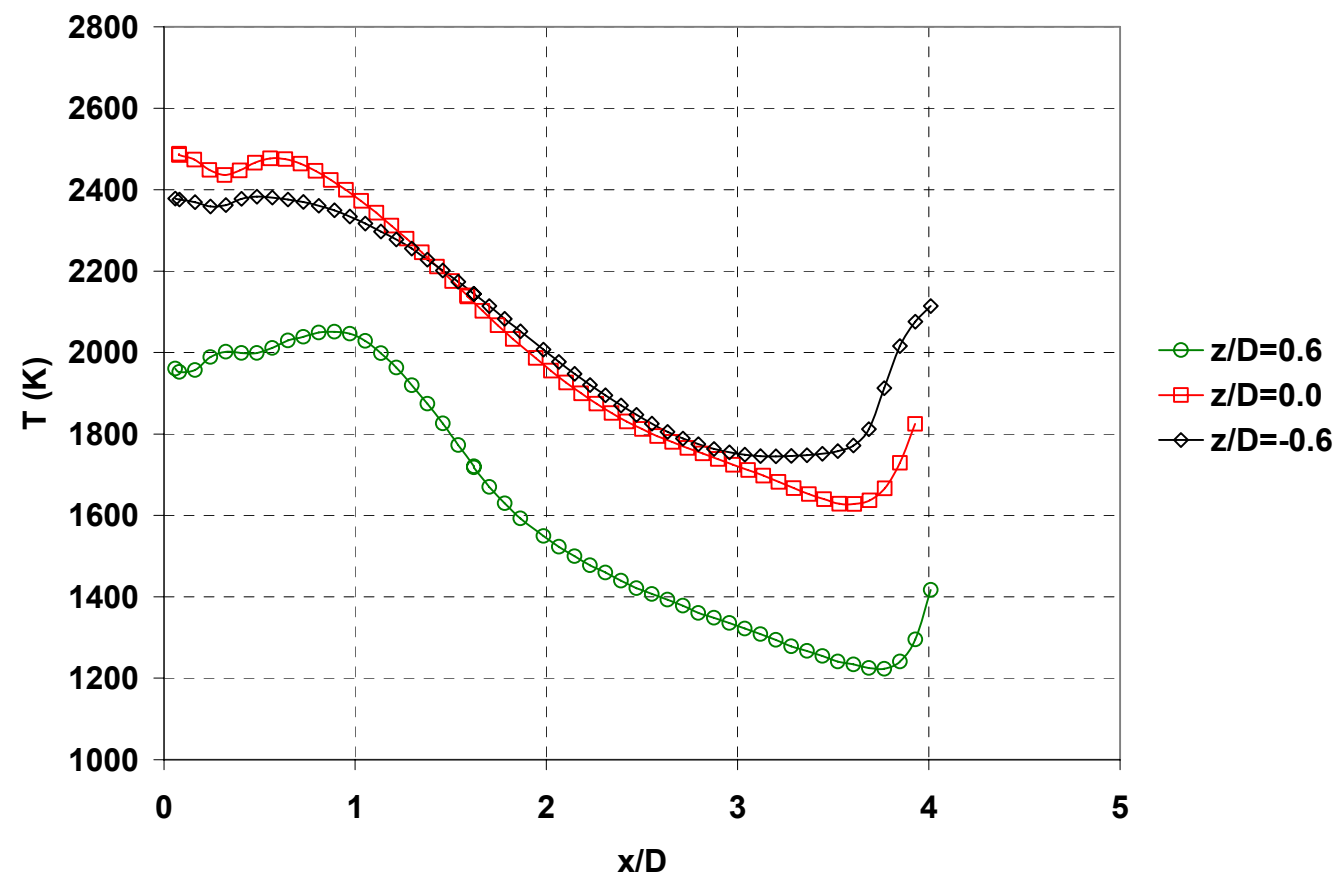

(b)

Figure 10: B-2 Flame-Deflector Surface Profiles Directly Under Engine Exhaust Plume (a) Pressure and (b) Temperature 
The center engine and off-center engine y-z cutting planes through the model are shown in Figures 11 and 12. Each cutting plane has been contoured by pressure, temperature and Mach number. The coalescence of the 5 engine plume appears to start occurring just downstream of the aspirator. This is indicated by a rapid expansion in the center engine plume shown in Figure 11, and merging of two of the off-center engine plumes as seen in Figure 11. Figures 11 and 12 also reveal that a significant flow reversal is occurring up the deflector surface back towards the aspirator in the form of an attached supersonic wall jet. As the reversed-flow wall jet travels up the deflector surface, it eventually impinges on the South-side bottom of the aspirator surface. After recirculating under the aspirator, the reversed flow is entrained back into the plume and convected out of the flame-deflector. Time-accurate simulations showed the reversed-flow wall jet to experience a strong instability in the form of an asymmetical flapping-jet as depicted in the time sequence of Figure 13. Strong transverse pressure waves are generated inside the flame-deflector that act to continually excite the impinging flow. However, over time, the average reversed flow was seen to be symmetrical. This reversed flow will potentially need to be addressed, in particular the water cooling requirements, through further investigation and modeling.

The overall plume structure development can be better visualized in Figures 14 and 15 . Figure 14 shows cross-section cuts through the plume contoured by temperature. The individual exhaust flows from the 5-engine cluster is evident in the first cross-cut. As the plume progressed through the aspirator and into the deflector, the five plumes began merging into a 4-lobe pattern. At the point of impingement, the 5 -engine plume had not completely coalesced into a single aggregate plume. This led to local hot spots on the deflector surface. Figure 14 shows that as the flow exited the deflector, a counter-rotating vortex pair was formed due to sidewall confinement of the deflector. The counter rotating-vortex pair entrained fresh cold-air from the surrounding which mixed with the hot plume serving to cool the exhaust flow as it expanded to the atmosphere. The counter-rotating vortex pair created a very unique thermal plume structure as shown in Figure 15. Figure 15 is an isothermal surface of $1000 \mathrm{~K}$ which has been contoured by the local Mach number. The strongly attached plume and its splashing on the deflector walls are quite evident from Figure 15. Also, some reversed flow up the deflector surface can be seen behind the downward exhaust of the ARES V engine cluster. Entrainment of fresh air by the plume back into the deflector is also visualized in Figure 15 by magenta streamlines that were emitted from a line located outside the test stand and above the deflector. 


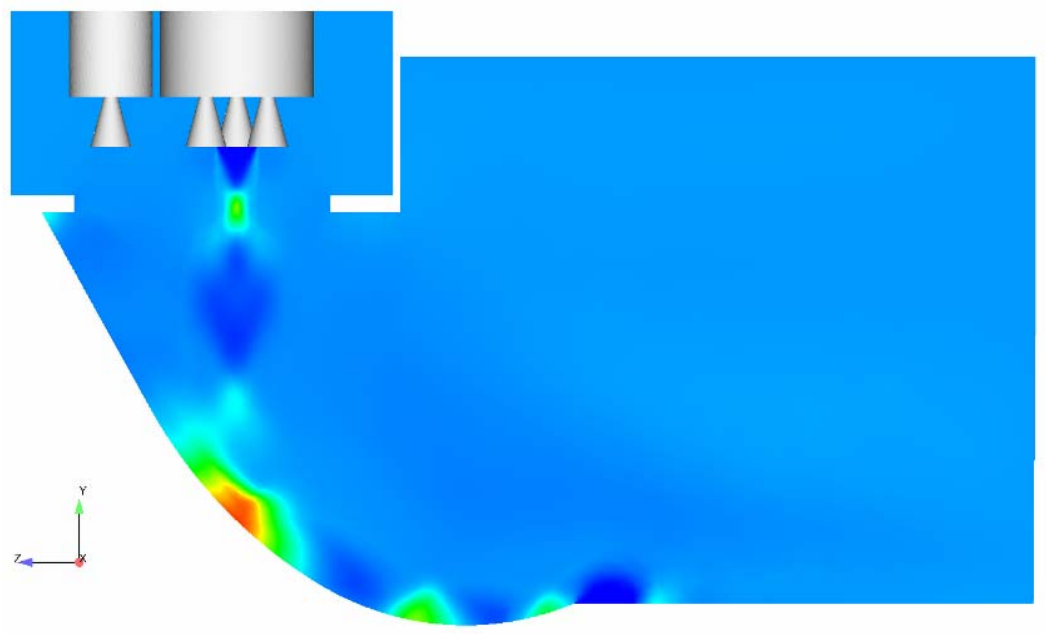

$\mathrm{P}(\mathrm{Pa})$

$4.2 \mathrm{e}+005$

$3.3 \mathrm{e}+005$

.

(a)

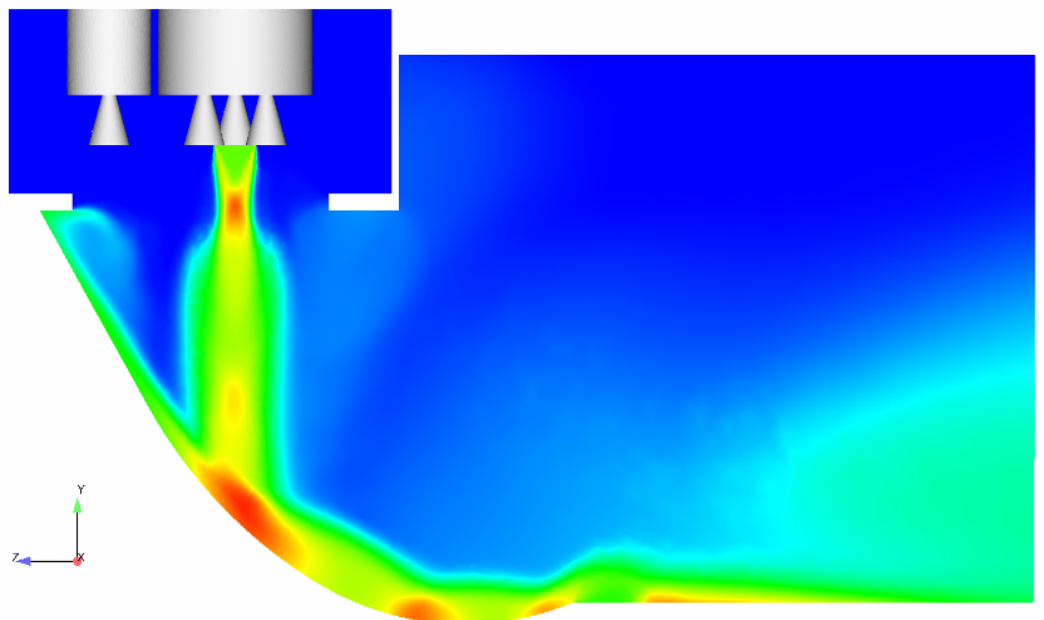

(b)
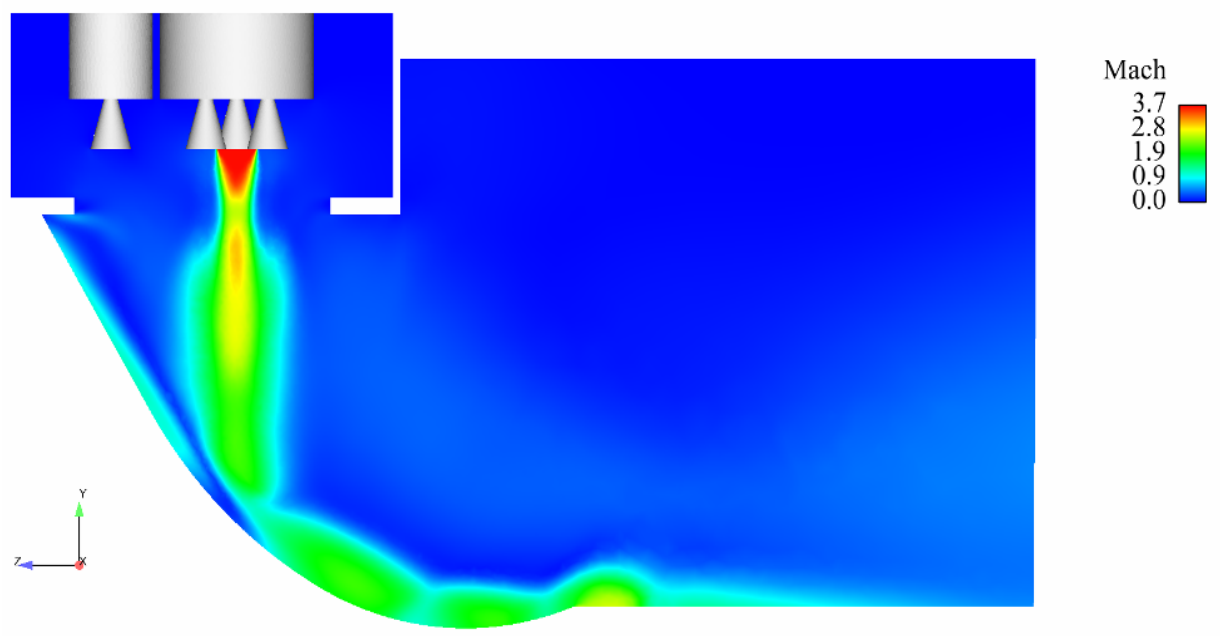

(c)

Figure 11: Time-Averaged Center Engine (Y-Z Plane) Contours - (a) Pressure, (b) Temperature and (c) Mach Number

15

American Institute of Aeronautics and Astronautics

RELEASED - Printed documents may be obsolete; validate prior to use. 


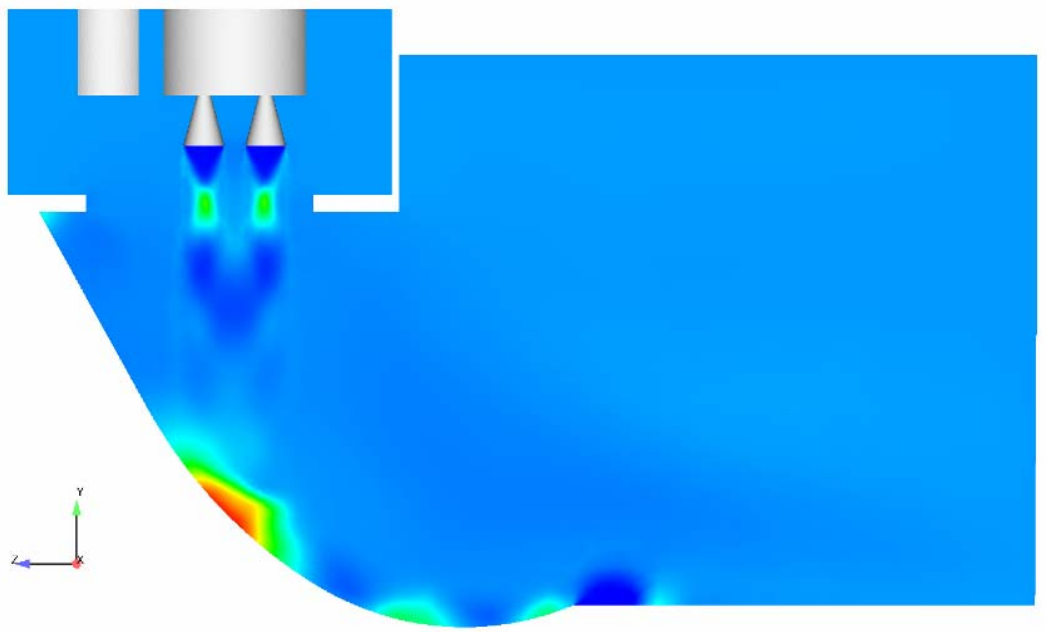

$\mathrm{P}(\mathrm{Pa})$

(a)
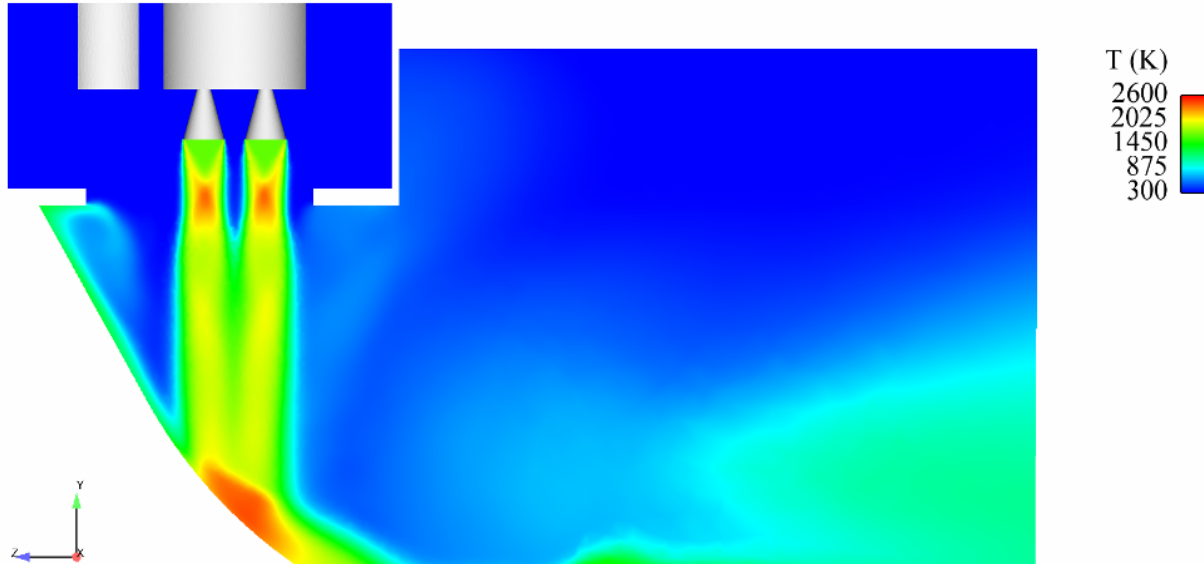

(b)
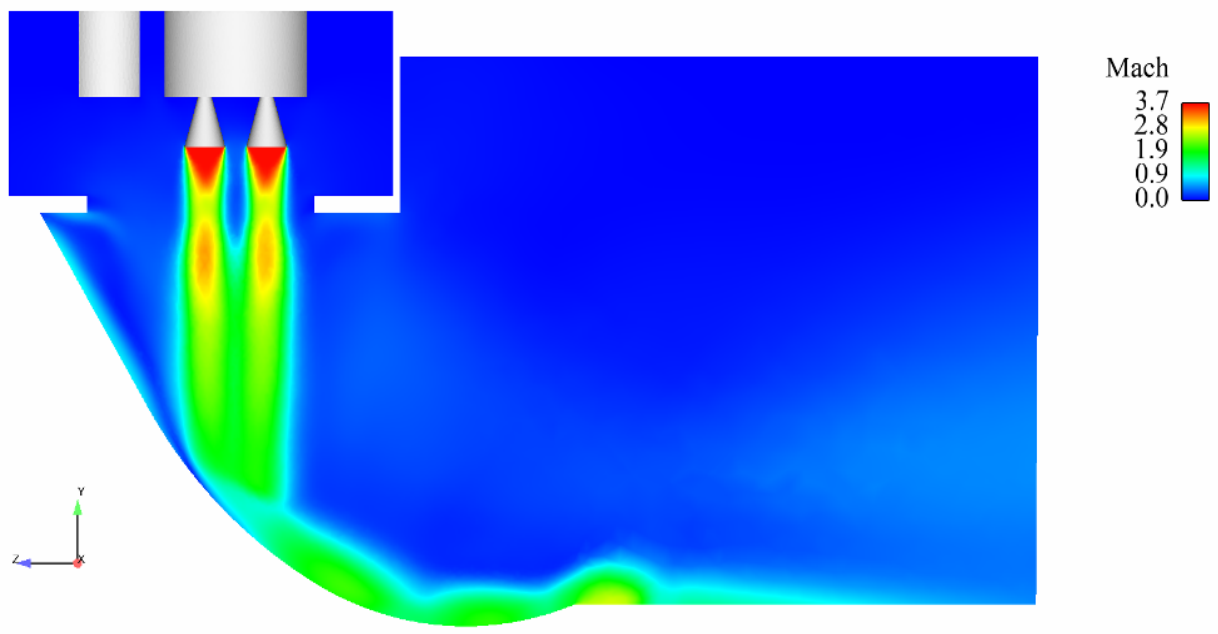

(c)

Figure 12: Time-Averaged Off-Center Engine (Y-Z Plane) Contours - (a) Pressure, (b) Temperature and (c) Mach Number 

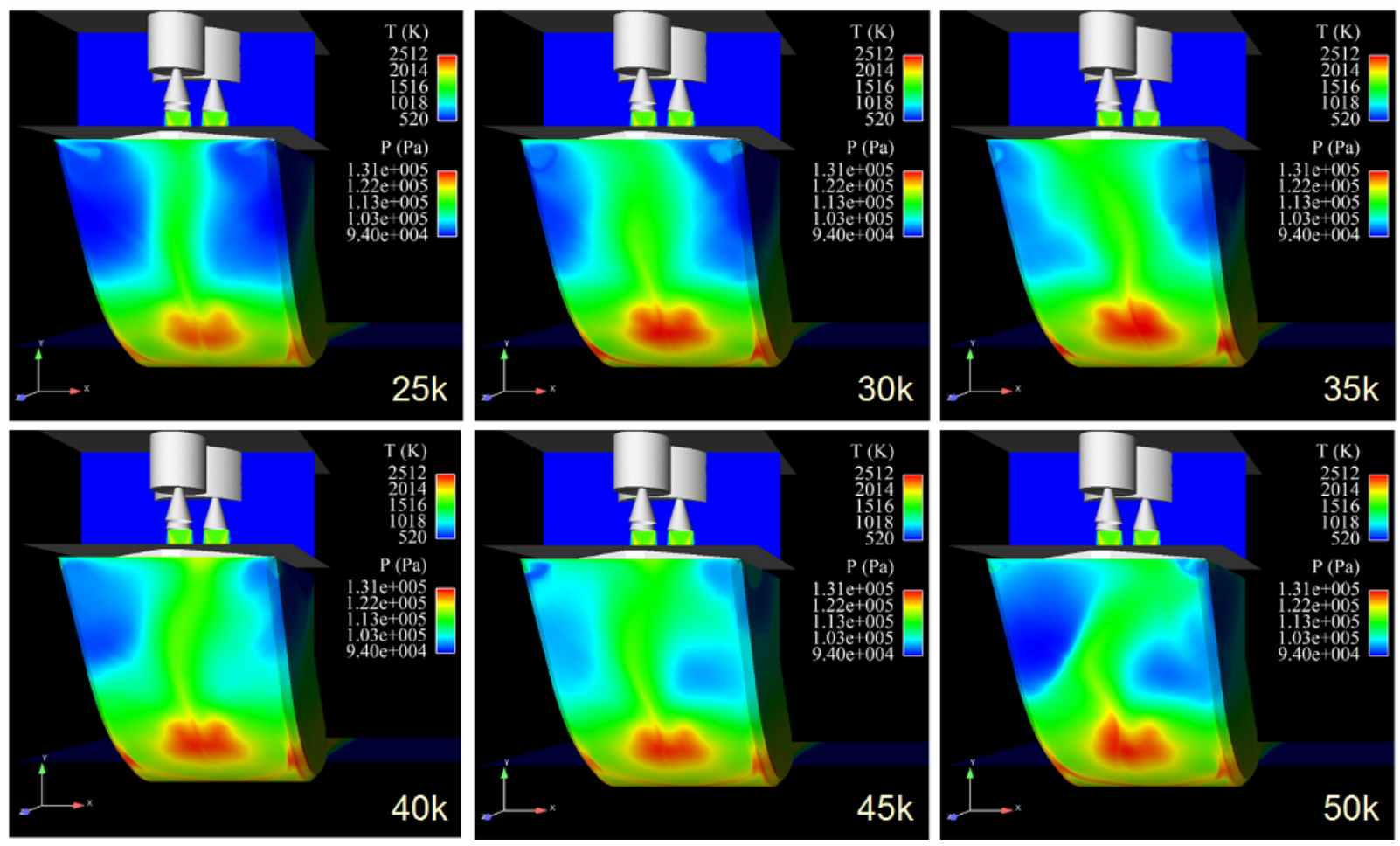

Figure 13: Unsteady ARES V Plume Impingement on B-2 Test Stand (Rear view of deflector wall temperatures are shown with the iteration number indicated)

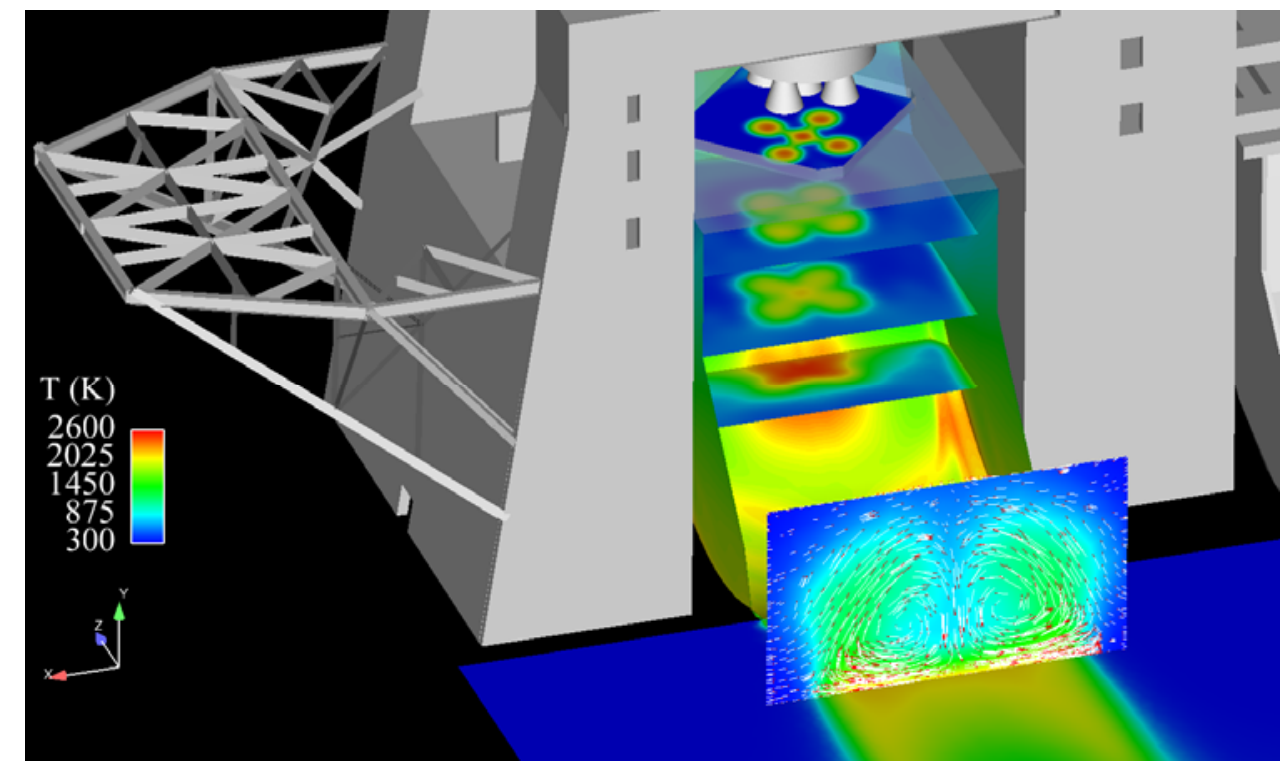

Figure 14: Time-Averaged ARES V Plume Cross-Section Temperature Contours 


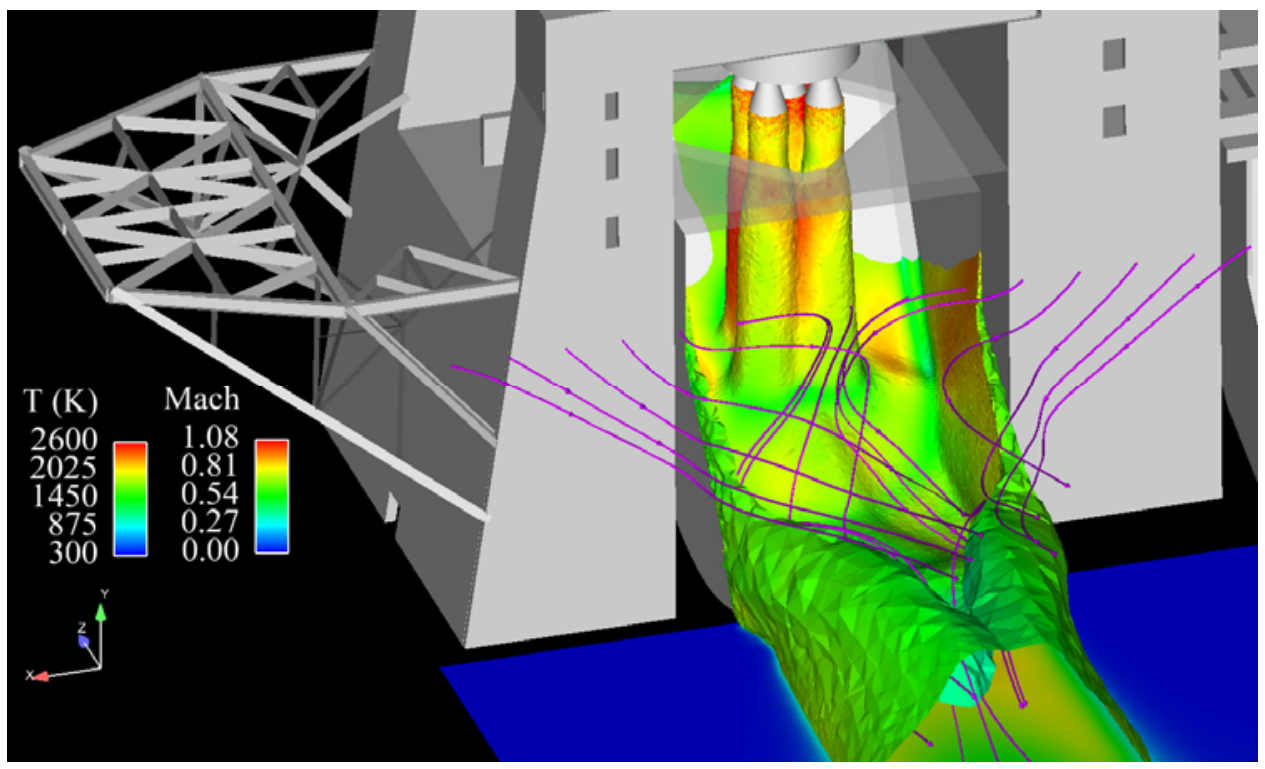

Figure 15: Time-Averaged ARES V Plume Isothermal Surface (1000K) Colored by Plume Mach Number with Representative Entrainment Streamlines (in magenta).

\section{Conclusion}

A computational fluid dynamics (CFD) modeling study was performed to quantify the plume-induced environment of a conceptual ARES V vehicle stage test at the NASA Stennis Space Center (NASA-SSC). A 4.2 million cell unstructured grid was generated for the NASA-SSC B-2 test stand with the ARES V stage being located in a proposed off-center forward position. The CRUNCH CFD code was used to simulate the cluster of five RS-68 LOX/LH2 engines from the ARES V stage as an inviscid, ideal-gas, chemically frozen flow. The NASA Chemical Equilibrium Code (CEA) was used to generate the appropriate nozzle exit conditions for the RS-68 engines. The time-averaged plume was captured and the impingement properties on the B-2 deflector were analyzed. The CFD results showed a non-coalesced plume impinging on the B-2 flame-deflector with a maximum un-cooled adiabatic impingement temperature and pressure of $2600 \mathrm{~K}$ and $4.32 \mathrm{e} 5 \mathrm{~Pa}$. These predictions were consistent with simplified analytical estimates. The CFD predictions predicted a non-negligible amount of reversed flow up the flame-deflector surface due to the larger impingement angle and associated detached deflector shock wave, indicating that significant modifications to the cooling-hole patterns would need to be made prior to conducting these tests. Modeling efforts are continuing for both the ARES V and ARES I state tests. Higher fidelity calculations are now being conducted where turbulent, finite-rate chemistry effects are being included in the models.

\section{Acknowledgments}

The financial support for this work through the direction of Bartt Hebert of NASA Stennis is greatly appreciated. The authors would also like to thank the technical consultation provided by Greg McVay of the NASA Test Operations Group. In addition, the technical and administrative support provided by Harry Ryan, Robert Field, Tom Jacks and David Coote of NASA Stennis are greatly appreciated.

\section{References}

1“Constellation Program: America's Fleet of Next-Generation Launch Vehicles - The Ares V Cargo Launch Vehicle", FS-2006-07-84-MSFC Pub 8-40599, National Aeronautics and Space Administration, George C. Marshall Space Flight Center, Huntsville, AL 35812. 
2“Constellation Program: America's Fleet of Next-Generation Launch Vehicles - The Ares I Crew Launch Vehicle", FS-2006-07-85-MSFC Pub 8-40598, National Aeronautics and Space Administration, George C. Marshall Space Flight Center, Huntsville, AL 35812.

${ }^{3}$ Dumbacher, D., "A New Heavy-Lift Capability for Space Exploration: NASA's Ares V Cargo Launch Vehicle," AIAA Space 2006 Conference, San Jose, CA, Sep. 19-21, 2006.

${ }^{4}$ Greenwood, T., Twichell, W., Ferrari, D., and Kuck, F., "Shuttle Derived In-Line Heavy Lift Vehicle," AIAA-2005-3816, 41st AIAA/ASME/SAE/ASEE Joint Propulsion Conference, Tucson, Arizona, July 10-13, 2005.

${ }^{5}$ Murphy, T., "RS-68 and Linear Aerospike," 50th International Astronautical Federation Congress, Liquid Rocket Propulsion, Oct. 1999.

${ }^{6}$ Bouley, S., "J-2X Engine", Plenary Panel - Constellation Elements (Orion, Ares, etc.), AIAA 2nd Space Exploration Conference, Houston, TX, Dec. 4-6, 2006.

${ }^{7}$ Snoody, J., "Development of the J-2X Engine for the ARES I Crew Launch Vehicle and the ARES V Cargo Launch Vehicle: Building on the Apollo Program for Lunar Return Missions", 57th International Astronautical Federation Congress, Valencia Spain, 2-6 Oct. 2006.

${ }^{8}$ Rahman, Shamim, "Liquid Rocket Engines", AIAA Short Course - Liquid Rocket Engines, 41st AIAA/ASME/SAE/ASEE Joint Propulsion Conference, Tuscon, Arizona, July 13-14, 2005.

${ }^{9}$ Tejwani, G., McVay, G., Langford, L. and St. Cyr, W., "Hydrocarbon-Fueled Rocket Engine Plume Diagnostics: Analytical Developments \& Experimental Results", AIAA-2006-4407, 42nd AIAA/ASME/SAE/ASEE Joint Propulsion Conference, Sacramento, California, July 9-12, 2006.

${ }^{10}$ Gordon, S. and McBride, B. J., "Computer Program for Calculation of Complex Chemical Equilibrium Compositions and Applications I. Analysis”, NASA RP-1311, Oct. 1994.

${ }^{11}$ Lamont, P. J. and Hunt, B. L., "The Impingement of Underexpanded, Axisymmetric Jets on Perpendicular and Inclined Flat Plates," Journal of Fluid Mechanics, Vol. 100, 1980.

${ }^{12}$ Hosangadi, A., Lee, R.A., York, B.J., Sinha, N. and Dash, S.M., "Upwind Unstructured Scheme for Three-Dimensional Combusting Flows," Journal of Propulsion and Power, Vol. 12, No. 3, May-June 1996, pp. 494-503.

${ }^{13}$ Hosangadi, A., Lee, R.A., Cavallo, P.A., Sinha, N., and York, B.J., "Hybrid, Viscous, Unstructured Mesh Solver for Propulsive Applications," AIAA-98-3153, AIAA 34th JPC, Cleveland, OH, July 13-15, 1998.

${ }^{14}$ Hosangadi, A., Cavallo, P.A., Arunajatesan, S., Ungewitter, R. and Lee, R.A., "Aero-Propulsive Jet Interaction Simulations Using Hybrid Unstructured Meshes," AIAA Paper-99-2219, 35th AIAA/ASME/SAE/ASEE Joint Propulsion Conference and Exhibit, Los Angeles, CA, June 20-24, 1999.

${ }^{15}$ Barth, T.J., "Numerical Aspects of Computing Viscous High Reynolds Number Flows on Unstructured Meshes,” AIAA Paper 91-0721, Jan. 1991.

${ }^{16}$ Barth, T.J., and Linton, S.W., "An Unstructured Mesh Newton Solution for Compressible Fluid Flow and Its Parallel Implementation," AIAA Paper 95-0221, 1995.

${ }^{17}$ Chidambaram, N., Kenzakowski, D.C., and Dash, S.M., "Application of Variable Turbulent Prandtl/Schmidt Methodology to Propulsive Flows," AIAA Paper No. 2000-0885 submitted for presentation at 38th AIAA Aerospace Sciences Meeting at Reno, NV, January 10-13, 2000.

${ }^{18}$ Calhoon, W., Jr., and Kenzakowski, D.C., " Evaluation Of A PDF Turbulent-Chemistry Interaction Model For Missile Exhaust Plume Analysis," AIAA Paper No. 2000-0187 submitted for presentation at 38th AIAA Aerospace Sciences Meeting at Reno, NV, January 10-13, 2000.

${ }^{19}$ Choi, Y-H. and Merkle, C.L., "The Application of Preconditioning to Viscous Flows," Journal of Computational Physics, Vol. 105, pp. 207-223 (1993). 